\title{
DESENVOLVIMENTO E TRABALHO: TUTELA DO AMBIENTE LABORAL PRODUTOR E DISTRIBUIDOR DE ENERGIA
}

\author{
Cristina Paiva Serafim Gadelha Campos \\ Professora da Universidade Estadual da Paraíba (UEPB), \\ mestre em Direito e Desenvolvimento Sustentável pelo \\ Centro Universitário de João Pessoa (UNIPE). \\ E-mail: cristinacampos_@hotmail.com \\ Flávia de Paiva Medeiros de Oliveira \\ Professora do Centro Universitário de João Pessoa-PB \\ (UNIPE), da Universidade Estadual da Paraíba (UEPB), \\ doutora em Direito do Trabalho e Previdência Social pela \\ Universidade de Valência (Espanha). \\ E-mail: flaviadepaiva@hotmail.com
}

RESUMO: O presente artigo científico pretende realizar um estudo do meio ambiente do trabalho produtor e distribuidor de energia, promovendo uma interface entre o Direito do Trabalho e o Direito Ambiental, que tem como ponto de partida a nova concepção de desenvolvimento cuja finalidade é promover o bem-estar do ser humano de maneira ampla. Essa nova concepção influi diretamente no trabalho desenvolvido na produção e distribuição de energia, que deve ser realizado em condições dignas. A salubridade desse meio ambiente influencia, diretamente, na vida dos trabalhadores e, indiretamente, dos consumidores desse bem essencial. Para tanto, foi utilizado o método indutivo e qualitativo, tendo sido realizada uma pesquisa bibliográfica, por meio da qual se chegou à conclusão de que o caráter difuso desse meio ambiente específico impõe a conjunção de esforços de toda a coletividade, trabalhadores, empresa e consumidores, para se garantir a sua higidez, já que, tanto usuários, quanto trabalhadores se beneficiam com condições de salubridade desse ambiente laboral.

PALAVRAS-CHAVE: Desenvolvimento; Trabalho; Proteção; Distribuição; Energia.

\section{Development and work: protection of producer and distributor of energy work's environment}

ABSTRACT: This scientific article intends to perform a study about the producer and distributor of energy work's environment, making a relation between the Labor Law and the Environmental Law, which begging is based on the new conception of development, oriented by the purpose of promote the human's being welfare, in a broad perspective. This new conception influences directly the production and distribution of energy, that have to be developed based on dignified conditions. The salubrity in this environment influences, directly, the workers' lives and, indirectly, the consumers' lives of this essential good. Therefore, was utilized the inductive and qualitative methods, performing a literature search, imposing the conclusion that the diffuse character of this particular environment needs the collective effort by the whole community, workers, company and consumers, for ensure its healthiness, considering that users and workers have benefits by salubrity conditions' in work's environment.

KEYWORDS: Development; Work; Protection; Distribution; Energy. 


\section{INTRODUÇÃo}

Com o passar do tempo, percebeu-se que traduzir o desenvolvimento pela ideia de crescimento econômico significa restringi-lo. Revelando-se como um processo multifacetado, que abrange um diversificado conjunto de elementos que têm como finalidade principal garantir o bem estar do homem, o desenvolvimento demonstra que o crescimento econômico merece ser visto como apenas um dos seus componentes. Destarte, constata-se que o reconhecimento da aproximação, e não da identificação, entre desenvolvimento e crescimento econômico conduz a um novo conceito de desenvolvimento, que notadamente engloba uma série de condições compatíveis com a qualidade de vida, inclusive, do ponto de vista social.

Considerando que o direito ao meio ambiente do trabalho equilibrado é corolário da garantia da vida com dignidade, tratando-se de verdadeiro direito fundamental do homem - por se apresentar como uma das facetas do direito ao meio ambiente equilibrado -, coaduna-se com a nova concepção de desenvolvimento. Isso porque o trabalho em condições adequadas dignifica o homem e lhe permite gozar de satisfação profissional, o que encontra amparo na nova concepção de desenvolvimento que deve ser buscada, construída e efetivada pela sociedade e pelo Estado.

Neste sentido, merece consideração o meio ambiente laboral responsável pela produção e distribuição de energia. Afora sua capacidade para conferir aos operários que nele trabalham a possibilidade de gozarem das sensações e benefícios que se espera de um ambiente de labor hígido, está dotado de aptidão para repercutir sobre uma infinidade de pessoas e situações, sejam elas direta ou indiretamente relacionadas à produção ou ao consumo da energia produzida.

Em outras palavras, o caráter difuso do direito ao meio ambiente equilibrado se revela com bastante evidência no ambiente que produz e distribui energia. A noção de desenvolvimento impõe o reconhecimento de que a essencialidade do bem lá produzido e distribuído suscita rigorosidade na observância de condições dignas de labor, já que estas refletirão na qualidade de vida de um número incontável de pessoas que já vivem e que ainda viverão, ainda afetando grandes quantidades de plantas, animais e recursos naturais.

Sendo assim, o presente trabalho procurará demonstrar que a concepção de desenvolvimento, notadamente na sua nova perspectiva, compatibiliza-se com o direito ao equilibrado meio ambiente produtor e distribuidor de energia. Destaca-se que para atingir os objetivos a que se propõe, será realizada uma pesquisa bibliográfica, que fará uso do método indutivo, por meio do qual se pretende analisar a nova concepção de desenvolvimento e sua relação com o meio ambiente equilibrado; e do qualitativo, através do qual se pretende avaliar o meio ambiente por uma perspectiva ampla, no qual se insere a dimensão laboral daqueles indivíduos implicados no processo de produção e distribuição de energia, a fim de demonstrar que o caráter difuso deste justifica um forte empenho dos âmbitos público e privado para sua garantia, sendo a educação ambiental e os princípios da prevenção e da precaução instrumentos facilitadores deste processo.

\section{EVOLUÇÃO dO CONCEITO DE DESENVOLVIMENTO}

Embora seja possível que o termo "desenvolvimento" assuma contornos próprios em cada segmento da sociedade, constata-se que sempre estará relacionado à ideia de progresso, avanços ou melhorias. Especificamente no campo econômico, a discussão acerca do vocábulo e seu significado social possibilitou várias construções conceituais e filosóficas, inspirando discussões em diversos segmentos correlacionados, sobretudo, devido a representatividade que a economia tem na sociedade hodierna (VITOR, 2015, p. 03). 
Também é possível destacar a atenção da ciência do direito em questões relacionadas ao desenvolvimento. Tendo em vista que esta apresenta uma preocupação natural com os fatores sociais, não impressiona constatar sua especial dedicação aos instrumentos jurídicos que promovem o desenvolvimento. Contudo, não vale esquecer que a abordagem jurídica do conceito de desenvolvimento tem suas origens no âmbito econômico.

Sendo assim, é relevante considerar as bases em que se assentam o pensamento econômico acerca do desenvolvimento. Sob esta ótica, o desenvolvimento sempre esteve relacionado ao crescimento econômico, de modo que um é sinônimo do outro. Procurando demonstrar o motivo de tal associação, Veiga (2010, p. 18-19) destaca que até os anos 1960, não se sentia a necessidade de distinguir desenvolvimento e crescimento econômico, já que as poucas nações desenvolvidas que existiam se tornaram ricas por meio da industrialização, enquanto os países subdesenvolvidos eram pobres e ainda não haviam passado por tal processo.

Neste sentido, é bastante importante o vínculo entre direito e desenvolvimento, considerando que o sistema jurídico de um país poderá usar os instrumentos de que dispõe para orientar seu desenvolvimento, identificando as falhas que a simples importação e aplicação da ideia econômica de desenvolvimento podem causar ao seu alcance. Inclusive, atualmente é possível constatar o empenho dos países desenvolvidos para que se concretizem reformas jurídicas nos países em desenvolvimento, reafirmando a influência do direito sobre o processo de desenvolvimento (DAVIS; TREBILOCOCK, 2009, p. 219).

Acerca da possibilidade de distinção entre desenvolvimento e crescimento econômico, experiências em diversos países, notadamente no século XX, demonstraram que não ocorre essa correspondência. Tais experiências estão baseadas na constatação de que países, passando por processos de desenvolvimento, tiveram forte crescimento de suas economias, mas não houve melhoria na qualidade de vida de seus cidadãos.

A experiência ocorrida no Brasil revela que o crescimento econômico foi impulsionado pelos interesses da elite, que apenas tinham em vista a manutenção de seus interesses e privilégios, sem valorizar quaisquer interesses sociais. Neste sentido, o crescimento econômico brasileiro esteve associado a um processo neoliberal, servindo para demonstrar que crescimento econômico não é sinônimo de desenvolvimento, considerando que, embora o fortalecimento da economia possibilitasse uma melhoria homogênea na qualidade de vida da população, este fim se tornaria dependente da acumulação de riquezas e do avanço tecnológico (VITOR, 2015, p. 04).

Percebendo que diversas outras nações semi-industrializadas passaram pela mesma experiência, notadamente na década de 1950, as evidências de que o intenso crescimento econômico não conduzia necessariamente ao maior acesso da população de baixa renda a bens culturais e materiais foram as principais responsáveis por demonstrar que desenvolvimento e crescimento econômico não são sinônimos, suscitando um debate internacional acerca do sentido daquele (VEIGA, 2010, p. 19).

Distinguindo crescimento e desenvolvimento, Furtado (2004, p. 484) aponta que o crescimento econômico se fundamenta na preservação do privilégio das elites que satisfazem o seu interesse de modernização. Para ele, por outro lado, o desenvolvimento pressupõe um projeto social subjacente, que não é sinônimo de ter recursos para investir, mas consiste na disposição de preparar um melhor futuro para a maioria da população, priorizando a efetiva melhoria das condições de vida da população.

Grau (2007, p. 216), por sua vez, também defende que desenvolvimento e crescimento econômico estão associados, tendo em vista que este faz parte daquele, mas não se confundem. Para o citado autor, a ideia de desenvolvimento implica em dinâmicas mutações e obriga a que 
se realize, na sociedade por ela abrangida, um processo de mobilidade social contínuo e intermitente. O processo de desenvolvimento deve levar a uma mudança de camadas da população de um estrato social para a outra, seguido da elevação do nível econômico e do nível cultural-intelectual e comunitário.

Quanto à literatura econômica dominante, duas correntes merecem ser consideradas, quanto à análise do desenvolvimento: a do novo institucionalismo e a que destaca valores e questões relacionadas à pobreza. A primeira destas correntes põe em relevo a influência das instituições no desenvolvimento da sociedade, demonstrando que sua evolução histórica, ou crescimento de longo prazo, encontra condicionamento na formação das instituições, bem como em suas evoluções. Sendo assim, analisa as maneiras pelas quais as instituições interferem nos comportamentos econômicos e sugere que o modelo de instituição deve estar baseado na diminuição dos custos de informação e transação, de modo que permaneça vinculado ao ambiente que ocasionou sua formação econômica (COUTINHO, BARACHO, 2013, p. 152-153). Já a segunda corrente vincula o desenvolvimento à liberdade, entendendo que aquele se efetiva por meio da possibilidade de as pessoas desfrutarem de liberdades reais. Destarte, tal corrente defende que o desenvolvimento é alcançado, exemplificativamente, quando são removidas a pobreza, a tirania, a falta de oportunidades econômicas, a excessiva interferência repressiva estatal e a falta de zelo dos agentes públicos no exercício de suas funções (COUTINHO, BARACHO, 2013, p. 153). Em outras palavras, esta corrente que analisa o desenvolvimento acredita que além do crescimento econômico, outros valores também lhe são necessários, especialmente valores éticos.

De acordo com Sachs (2009), o desenvolvimento deve ser visto como o alcance, por toda a população, de direitos plenos de cidadania. Nesta perspectiva, às gerações presentes e futuras devem ser oferecidas condições de acesso à cidadania, o que implica na necessidade de sustentabilidade dos setores que, juntos, conduzem ao desenvolvimento.

Quanto à concepção de desenvolvimento elaborada por Sen (2007, p. 51-52), a qual notadamente valoriza uma visão ética do desenvolvimento, eis algumas de suas palavras:

\begin{abstract}
Ver o desenvolvimento a partir das liberdades substantivas das pessoas tem implicações muito abrangentes para nossa compreensão do processo de desenvolvimento e também para os modos de promovê-lo. Na perspectiva avaliatória, isso envolve a necessidade de aquilatar os requisitos de desenvolvimento com base na remoção das privações de liberdades que podem afligir os membros da sociedade. O processo de desenvolvimento, nessa visão, não difere em essência da história do triunfo sobre essas privações de liberdade. Embora essa história não seja de modo algum desvinculada do processo de crescimento econômico e de acumulação de capital físico e humano, seu alcance e abrangência vão muito além dessas variáveis.
\end{abstract}

Sendo assim, percebe-se que esta última corrente da literatura econômica, que a destaca a superação da pobreza como um dos fatores que deve ser levado em conta para aferir o desenvolvimento, é marcadamente mais equilibrada e aproximada da ética. Destarte, a compreensão do processo de desenvolvimento passa a se distanciar dos fundamentos que a esfera econômica havia lhe dado, sendo visto como instrumento à serviço do bem-estar dos seres humanos.

Passou-se a assimilar que o desenvolvimento deve estar associado à garantia da mais ampla inclusão social possível, para o que se faz imprescindível o autoconhecimento da sociedade, permitindo a identificação de princípios e valores que, controlando a esfera econômica, conduzam a uma democracia econômica (SALOMÃO FILHO, 2002, p. 32). Sendo assim, a economia passou a ser vista como mais um instrumento a ser utilizado para a satisfação do ser humano, assim como também devem ser as estruturas sociais, os aspectos culturais e a aplicação dos recursos estatais. 
Portanto, as necessidades humanas foram consideradas as principais orientadoras do processo de desenvolvimento. $\mathrm{O}$ aumento de indicadores do nível de acesso à educação e à saúde básica, bem como a diminuição do índice de mortalidade infantil e a melhoria dos demais índices do nível de vida receberam valorização incomparável perante índices de aumento de renda.

Tavares (2011, p. 63) elaborou um conceito de desenvolvimento que traduz bem a nova visão deste processo, uma vez que realça que o avanço econômico desacompanhado do desenvolvimento do cidadão terá pouco significado. De acordo com o autor, o desenvolvimento do Estado passa, necessariamente, pelo desenvolvimento do homem e de seus direitos fundamentais.

Neste sentido, Bercovici (2005, p. 53) diferencia desenvolvimento e modernização, destacando que aquele somente é alcançado quando ocorre uma transformação nas estruturas sociais e econômicas, através de uma política deliberada de desenvolvimento que, além de garantir o desenvolvimento econômico, garanta o desenvolvimento social, sem o que se estará diante, apenas, de um processo de modernização.

Destarte, a discussão acerca da sustentabilidade se torna imprescindível em meio à análise do processo de desenvolvimento. Sendo este concebido como instrumento que deve conduzir à valorização humana, a necessidade de associar o crescimento da sociedade ao seu desenvolvimento implica na preocupação com a sustentabilidade do processo de crescimento econômico.

A evidência de que a sustentabilidade faz parte do desenvolvimento encontra fundamento na nova visão multidimensional deste, com destaque para a abordagem ecológica que passou a compreender. As antigas concepções de desenvolvimento se tornaram ultrapassadas através da constatação de que a sustentabilidade ambiental deve fazer parte do crescimento e da melhoria da qualidade de vida, partindo do pressuposto de que as pressões suportadas pela biosfera estão prejudicando o desenvolvimento e as condições de vida humanas (VEIGA, 2010).

Em suma, a ideia de desenvolvimento pautado na sustentabilidade visa deixar claro o vínculo que deve existir entre crescimento econômico e meio ambiente. Veiga aponta que o surgimento da expressão "desenvolvimento sustentável” remonta ao debate, principalmente americano, acerca da possibilidade de uma explosão demográfica, associada ao perigo da eclosão de uma guerra nuclear ou precipitação decorrente da realização destes tipos de testes (VEIGA, 2010, p. 114). De acordo com o autor, este debate, ocorrido na década de 1960, repercutiu na polarização do "crescimento econômico" versus "preservação ambiental".

Portanto, a expressão "desenvolvimento sustentável” passou a substituir a terminologia "ecodesenvolvimento", utilizada na década de 1970 (VITOR, 2015, p. 05). O desenvolvimento assentado na sustentabilidade deve conciliar a eficiência (evidência de ser economicamente sustentado) com a inclusão (evidência de ser socialmente desejável) e o equilíbrio (evidência de ser ecologicamente prudente).

Assimilando a noção de desenvolvimento sustentável, a questão do meio ambiente foi definitivamente incluída na agenda internacional pela Conferência das Nações Unidas sobre o Ambiente Humano, em 1972. Além disso, percebe-se a consolidação de um intenso processo de legitimação e institucionalização normativa do termo "desenvolvimento sustentável”.

O início desse processo, de acordo com Veiga (2010, p. 113), remonta ao ano de 1987. Neste, a presidente da Comissão Mundial sobre o Meio Ambiente e Desenvolvimento, Gro Harlem Brundtland, afirmou, diante da Assembleia Geral da ONU, que o desenvolvimento sustentável é caracterizado como um "conceito político", além de um "conceito amplo para o progresso econômico e social"'. 
Sendo assim, a noção de desenvolvimento sustentável é imprescindível à constatação de que o crescimento econômico é capaz de conduzir à melhoria do bem-estar humano. Esta ideia - que aduz à nova concepção de desenvolvimento - deixa claro que o crescimento econômico de um país deve ser cuidadosamente orientado para que não interfira no equilíbrio ecológico, o qual, indiscutivelmente, também é instrumento participante do processo de desenvolvimento, e, inclusive, do desenvolvimento social.

\section{DESENVOLVIMENTO E DIREITO AO MEIO AMBIENTE DO TRABALHO EQUILIBRADO}

A nova concepção de desenvolvimento, marcadamente assentada nas ideias de que o bemestar humano é sua principal diretriz e de que o crescimento econômico se revela como apenas uma de suas facetas, é perfeitamente compatível com a valorização do direito ao meio ambiente do trabalho equilibrado. Na verdade, aquela concepção não somente se compatibiliza com este, como também exige sua valorização.

A evidência desta relação, que coloca a noção de desenvolvimento e o direito fundamental ao meio ambiente do trabalho equilibrado em polos próximos, pode ser vista considerando os elementos que caracterizam o referido direito fundamental. Observando as diretrizes que o orienta, percebe-se que além de merecer a máxima proteção pelo sistema jurídico do país, o direito ao equilíbrio do meio ambiente laboral deve fazer parte do projeto desenvolvimentista efetivamente assumido pelo Estado.

Portanto, a ideia de desenvolvimento deve fazer parte do conjunto de elementos que compõem o meio ambiente laboral. Como salientam Oliveira e Oliveira (2012, p. 150), o ambiente laboral não deve conferir ao trabalhador tão somente uma defesa frente aos riscos físicos ou químicos, mas também uma tutela social, oportunizando sua inserção na sociedade.

Sendo assim, é importante destacar que o direito ao meio ambiente do trabalho equilibrado se traduz pela garantia de condições mínimas que assegurem qualidade de vida razoável ao trabalhador (PADILHA, 2002, p. 41). Neste sentido, suscita condições dignas de trabalho em tudo aquilo que esteja relacionado ao ambiente onde o empregado exerce seu labor, envolvendo todo o complexo de bens materiais e imateriais que fazem parte do processo produtivo desenvolvido pelo homem. Demonstrando a complexidade de elementos que fazem parte do meio ambiente laboral - a qual, necessariamente, deve estar caracterizada pelo atributo do "equilíbrio", sob pena de não se adequar ao postulado do desenvolvimento -, Nascimento (1999, p. 583) destaca que o meio ambiente do trabalho compreende o conjunto de todos os equipamentos de trabalho e instalações nas quais o obreiro laboral, que formam o complexo máquina-trabalho.

Fazendo referência ao complexo de elementos que compõem o meio ambiente do trabalho, a doutrina aponta que aquele corresponde ao conjunto de bens imóveis e móveis de uma empresa e de uma sociedade, sobre os quais incidem direitos subjetivos privados, e direitos invioláveis de saúde e de integridade física dos trabalhadores que interagem no referido espaço laboral (SILVA, J., 1995, p. 05).

No mesmo sentido, Rocha (1997, p. 30) destaca que a ambiência onde se desenvolvem as atividades do trabalho humano ultrapassa os limites do espaço da fábrica ou empresa, englobando uma série de elementos, além do trabalhador. Por isso, considera como tal o espaço no qual se desenvolvem as atividades do trabalho humano, não se limitando ao empregado, mas dizendo respeito também a todo trabalhador que cede a sua mão-de-obra para o processo produtivo, tendo ele vínculo empregatício ou não. Tal ampliação das fronteiras do ambiente de trabalho 
para abranger, tanto o trabalhador subordinado, quanto o que não possui subordinação, atende às modificações por que passa o trabalho, pelo que o meio ambiente laboral não se restringe ao espaço interno da fábrica ou da empresa, mas se estende ao próprio local de moradia ou qualquer outro ambiente urbano no qual o trabalho aconteça.

Também vale salientar a definição de meio ambiente do trabalho equilibrado elaborada por Fiorillo (2000, p. 21), que evidencia a necessidade de que esse micro ambiente seja organizado de modo a garantir a salubridade do meio e a ausência de agentes que comprometam a incolumidade físico-psíquica dos trabalhadores, independente da condição que ostentam.

Em vista de tais considerações acerca do meio ambiente do trabalho, percebe-se que sua definição já demonstra a necessidade de que esteja em consonância com a ideia de equilíbrio. Considerando que é no ambiente laboral onde o homem passa grande parte de sua vida, tendo como principais objetivos o recebimento da remuneração que assegura sua sobrevivência e o alcance de sua realização profissional, não restam dúvidas de que aquele assume natureza jurídica de direito fundamental.

Seguindo esta lógica, a doutrina aponta que a consagração dos direitos de personalidade deve garantir a dignidade do empregado; para tanto, utilizam as seguintes palavras: “[...] há que se ter e manter a dignidade humana mesmo enquanto se trabalha, pois o trabalho, além de contribuir para o desenvolvimento do negócio, contribui para a sua vida digna. Os direitos de personalidade têm o papel de assegurar a dignidade ao trabalhador." (GONÇALVES; LOPES, 2013, p. 16). Partindo do pressuposto de que o meio ambiente laboral equilibrado é indispensável para a concretização do direito à vida com qualidade, resta nítida a associação entre a noção de desenvolvimento sustentável e o direito ao meio ambiente do trabalho equilibrado.

Neste sentido, vale destacar a importância da proteção ao meio ambiente do trabalho, enquanto corolário do processo de desenvolvimento sustentável. Considerando que o fim último deste é o bem-estar humano, e ainda tendo em vista a representatividade do labor para o homem, impõe-se a necessidade de preservação do ambiente em que o trabalho é exercido, bem como de tudo aquilo que é apresentado ao empregado em virtude de seu trabalho. Isto nada mais seria do que o atendimento ao necessário apelo do ser humano enquanto figura principal do processo de desenvolvimento sustentável, que almeja a possibilidade de ter uma vida profissional que lhe assegure nada mais do que condições propícias ao alcance daquilo que seu trabalho deve lhe proporcionar, notadamente condições de livremente exercer seu labor e, então, gozar de satisfação profissional.

O fundamento de que o meio ambiente laboral equilibrado faz parte do processo de desenvolvimento também pode ser percebido, com clareza, quando se constata que o direito fundamental ao meio ambiente equilibrado merece ser interpretado de forma ampla, abrangendo o meio ambiente laboral.

Amparando-se na diretriz de que o meio ambiente saudável é um dos pressupostos para a efetivação do direito à vida, o legislador constituinte brasileiro assimilou a ideia contida na Declaração do Meio Ambiente, fruto da Conferência de Estocolmo de 1972, e consagrou o direito ao meio ambiente equilibrado como direito fundamental, na Constituição Federal de 1988 (COSTA, 2013). Ao fazê-lo, sobretudo no momento em que utiliza a expressão "sadia qualidade de vida" (art. 225, caput, CF/88), o constituinte pátrio demonstrou preocupação com a vida humana, procurando instrumentalizar o meio ambiente para o alcance de condições de vida humana satisfatórias.

Assim, resta claro que o meio ambiente merece ser tutelado sob todos os aspectos que favoreçam à sadia qualidade de vida, sendo a conotação ecológica apenas um deles. O meio 
ambiente laboral, por sua vez, também é importante faceta da vida do homem, revelando-se como um elemento que indubitavelmente influencia nas condições de vida humana. Como consequência, resta a conclusão de que o meio ambiente do trabalho está abrangido pela conotação de direito fundamental conferida ao meio ambiente em geral. E mais: sua proteção, enquanto direito fundamental, coaduna perfeitamente com a noção de desenvolvimento sustentável, sendo este um fundamento decisivo para sua inclusão na concepção de meio ambiente equilibrado e merecedor da máxima proteção constitucional.

Como a Carta Magna brasileira tutela a dignidade e o bem-estar para que se concretize a sadia qualidade de vida, seria impensável pressupor que o meio ambiente - enquanto interação entre os seres vivos e o seu meio, merecendo destaque a relação do homem com o meio ambiente, de diversas formas - que se procura preservar é exclusivamente o natural. Perseguindo a intenção do constituinte, constata-se que visava à preservação da qualidade de vida em quaisquer das manifestações da interação entre o homem e o meio, podendo este ser qualificado como natural, cultural, artificial ou do trabalho.

Por isso, sob pena de se desviar do objetivo buscado pela Constituição Federal, bem como focando no que interessa ao nosso trabalho, destaca-se que não há razões para defender que o meio ambiente do trabalho não está incluído no conceito de meio ambiente equilibrado, consagrado como direito fundamental de todos.

Ademais, esta é mais uma faceta do processo de desenvolvimento sustentável, que, por sua vez, visa à canalização de todos os instrumentos para a garantia do bem-estar humano. Seria impossível alcançar a qualidade de vida se não houvesse a qualidade de trabalho (OLIVEIRA, 1998). Destarte, também não seria possível atingir um meio ambiente equilibrado e sustentável se o meio ambiente do trabalho restasse ignorado.

Isso porque o trabalho, como valor social, assume papel relevante no contexto constitucional. No texto do art. $1^{\circ}$, IV, assume o caráter de fundamento da República Federativa do Brasil. No art. 170, caput, erige-se como um dos fundamentos da ordem econômica, ao lado da livre iniciativa, cuja finalidade é assegurar a todos os indivíduos existência digna. No texto do art. 193, aparece como primado da ordem social.

Disso decorre que, sob o prisma da ordem econômica, o trabalho figura como um instrumento produtor de riquezas, que se expressa através da relação de emprego e de trabalho, por meio das quais ao correspondente dispêndio de força laborativa deve equivaler uma retribuição, que funciona como um dos eixos que viabilizam o desenvolvimento econômico da nação (RODRIGUES, 2003, p. 12). Sob o viés da ordem social, o trabalho aparece como um dos instrumentos para a concretização de uma ordem social justa e solidária, o que pressupõe que se busque por completo o trabalho, tanto pelos poderes constituídos, como também, e, principalmente, pela sociedade (FINATI, 1996, p. 28). Tudo isso com vistas a garantir que o trabalho seja, tanto do ponto de vista social, quanto sob o prisma jurídico, um elemento viabilizador da dignidade humana e do desenvolvimento social, que jamais poderão ser concretizados em desrespeito à integridade dos trabalhadores e da sociedade em geral.

\section{MEIO AMBIENTE LABORAL EQUILIBRADO DE PRODUÇÃO E DISTRIBUIÇÃO DE ENERGIA À SERVIÇO DO DESENVOLVIMENTO}

O meio ambiente do trabalho onde são operadas a produção e distribuição da energia se revela, dentre outras caracterizações possíveis, como um instrumento que permite que o homem desfrute de um dos bens imprescindíveis à sua qualidade de vida e regular desenvolvimento de 
suas atividades cotidianas. Sendo assim, diante da significativa representação que tem para a vida humana - sobretudo ao considerar que o citado meio ambiente diz respeito ao complexo máquina-trabalho que torna possíveis as atividades de produção e distribuição do bem energético - , merece ser cuidadosamente preservado.

Estando inserido na conotação de meio ambiente laboral, constata-se que o meio ambiente do trabalho ora especificado é merecedor da qualificação de direito fundamental. Salienta-se, em acréscimo, que inúmeras razões tornam tal caracterização realmente merecida, assentadas na ideia de que além de oferecer ao homem a oportunidade de se realizar profissionalmente e perceber remuneração, o referido meio ambiente laboral é capaz de lhe oferecer um bem precioso.

É indiscutível a dependência que o homem moderno apresenta da energia, bem como que sofreria bastante - seja no âmbito doméstico, cultural, profissional, científico ou em qualquer outro - se não mais pudesse dela usufruir. Diante disto, é notória sua relação com o processo de desenvolvimento, já que apresenta significativa importância para uma boa qualidade de vida humana.

Neste sentido, a relação entre o equilíbrio do meio ambiente produtor e distribuidor de energia e o desenvolvimento pode ser evidenciada, de forma concreta, sobretudo, através da análise de indicadores relativos a condições sociais. Neste sentido, oportunas são as palavras de Goldemberg (1998, p. 01):

ENERGIA É um ingrediente essencial para o desenvolvimento, que é uma das aspirações fundamentais da população dos países da América Latina, Ásia e África. O consumo de energia per capita pode ser usado como um indicador da importância dos problemas que afetam estes países, onde se encontram $70 \%$ da população mundial. Nos países em desenvolvimento mais pobres: a expectativa de vida é $30 \%$ menor; a mortalidade infantil, superior a 60 por 1000 nascimentos, é inferior a 20 nos países industrializados; analfabetismo supera a taxa de $20 \%$; número médio de filhos é maior do que dois em cada família e a população está crescendo rapidamente; nos países industrializados, ele é igual a dois, que é justamente o necessário para manter o equilíbrio populacional. Na maioria dos países, nos quais o consumo de energia comercial per capita está abaixo de uma tonelada equivalente de petróleo (TEP) por ano, as taxas de analfabetismo, mortalidade infantil e fertilidade total são altas, enquanto a expectativa de vida é baixa. Ultrapassar a barreira $1 \mathrm{TEP} /$ capita parece ser, portanto, essencial para o desenvolvimento. À medida em que o consumo de energia comercial per capita aumenta para valores acima de 2 TEP (ou mais), como é o caso dos países desenvolvidos, as condições sociais melhoram consideravelmente. $\mathrm{O}$ consumo médio per capita nos países industrializados da União Européia é de 3.22 TEP/ capita; a média mundial é de $1.66 \mathrm{TEP} /$ capita.

A energia exerce um papel instrumental no processo de desenvolvimento social e humano. Representa um elemento capaz de impulsionar atividades básicas e necessárias à sobrevivência e ao bem estar do homem, viabilizando a efetivação de condições que promovem o seu crescimento individual e coletivo. Seja para coisas simples - como preparar alimentos - seja para atividades bastante complexas - como auxiliar na fabricação de um meio de transporte que se locomova no espaço aéreo e transporta pessoas e objetos -, o homem utiliza a energia. Em outras palavras, a impossibilidade do desfrute deste bem inviabilizaria atividades que o ser humano exerce cotidianamente e que se tornaram indispensáveis para sua qualidade de vida.

Sendo assim, percebe-se que a efetivação do direito ao equilibrado meio ambiente laboral produtor e distribuidor de energia se compatibiliza com a ideia de desenvolvimento sustentável. Imperioso asseverar, ainda, que isto não somente é constatado sob o ponto de vista dos operários que laboram no setor e merecem gozar de condições dignas de trabalho, mas também sob o ponto de vista da população em geral, que tem a oportunidade de usufruir do bem produzido no espaço laboral respectivo. 
Especificamente no que tange aos perigos e riscos aos quais os profissionais do ramo de geração e distribuição de energia estão expostos, merece revelo o quanto estão sujeitos a lesões e doenças ocupacionais, com destaque para as consequentes de atividades repetitivas, da exposição a ambiente perigoso e/ou insalubre, ou mesmo da sujeição a campos eletromagnéticos especificamente quanto aos operários dos setores de produção e distribuição da energia elétrica. Além disso, deve-se levar em consideração que a excessiva autoconfiança dos respectivos profissionais representa fator que maximiza o risco de sofrerem lesões e doenças ocupacionais em virtude das atividades profissionais por eles desenvolvidas.

Com efeito, deve-se conjugar o fato de que o labor associado ao bem energético - especificamente à energia elétrica - é naturalmente uma ocasião que oferece riscos à vida e integridade física dos seus operários à constatação de que o excesso de autoconfiança, ou mesmo o desconhecimento de onde está a eletricidade, tornam a enfocada atividade laborativa um mecanismo que denota elevado risco à saúde e vida humanas. Exemplificadamente, o uso de equipamentos e materiais de proteção inadequados, o labor desenvolvido em meio a instalações desatentas às normas de segurança e proteção, ou mesmo falhas e desgastes no maquinário utilizado podem causar incêndios; além disso, o contato indevido com partes energizadas permite que a corrente elétrica percorra o corpo humano e cause queimaduras, internas ou externas, bem como lesões físicas e traumas psicológicos (SILVA, M., 2012, p. 01).

Em vista disso, a seção da medicina do trabalho dedicada à saúde do empregado (então conhecida por Segurança do Trabalho) dispensa cautelosa preocupação com o labor daqueles que são responsáveis profissionalmente pela produção e distribuição de energia, especificamente da eletricidade. A edição da NR-10 é uma demonstração das referidas preocupação e cautela, ao mesmo tempo em que merece sua breve análise, especialmente para constatar as doenças e lesões ocupacionais que reconhece serem passíveis de acometer o operariado do ramo energético (ROZA FILHO, 2012, p. 45).

Pela sua leitura, percebe-se que a intensidade da corrente elétrica contactada, o caminho percorrido pela eletricidade ao longo do corpo e a duração do choque são decisivos para determinar os possíveis males que o empregado sofrerá em sua saúde. Quanto à ocorrência de acidentes, trabalhador acometido por choque elétrico poderá sofrer lesões de quatro naturezas: eletrocução (fatal, sendo comumente provocada por raios e fios de alta tensão, poças d'água, roupas molhadas, umidade elevada ou suor), choque elétrico (causado por corrente elétrica que atravessa o corpo humano, ou mesmo de um animal), queimaduras (sendo mais perigosas em corpos molhados) e quedas provocadas pelo choque (SILVA, M., 2012, p. 01).

Por outro lado, lesões e doenças ocupacionais também podem ser provocadas no ambiente laboral produtor e distribuidor da energia, sem que tenham ocorrido quaisquer acidentes de trabalho (ROZA FILHO, 2012, p 64). Desse modo, pela leitura da NR-10, denota-se que a utilidade do bem energético não deve ser entendido como pressuposto para sua geração e distribuição a qualquer custo, notadamente ao evidenciar que detém a potencialidade de prejudicar a coagulação do sangue, provocar queimaduras de até terceiro grau, lesão nos nervos, contração muscular e reação nervosa de estremecimento (sensação de choque), a qual pode resultar na queda do indivíduo (de uma escada, árvore ou muro, por exemplo) ou contato com equipamentos perigosos. (SILVA, M., 2012, p. 01)

Portanto, levando em consideração a possibilidade de que o labor relacionado às atividades de produção e distribuição de energia, sobretudo elétrica, pode causar revezes à saúde do homem, inclusive levando-o a óbito, a NR-10 não se limitou a elencar os riscos que oferece, mas também previu mecanismos atinentes ao seu combate. Nesse sentido, destaca a técnica do aterramento e dicas básicas de segurança, tais como correspondência entre valor do disjuntor ou 
fuzível e a fiação; tamanho da bitola para circuito de lâmpadas; cuidados com quadros de luz e com o fio terra dos aparelhos. (SILVA, M., 2012, p. 01)

Ainda no tocante à constatação e prevenção dos riscos oferecidos ao operário do setor energético, cabe mencionar que o âmbito jurídico brasileiro, como um todo, os reconhece, não se limitando ao campo legislativo. Exemplo disso pode ser visto na órbita jurisprudencial através de decisão do Supremo Tribunal Federal (STF), datada de 08 de junho de 2016, por meio da qual a referida Corte reconheceu que campos eletromagnéticos afetam a saúde da população, merecendo ter suas dimensões limitadas. Em vista disso, por meio de solução dotada de repercussão geral, ficou estabelecido que devem ser adotados os padrões propostos pela OMS, enquanto não houver certeza científica acerca dos efeitos nocivos da exposição ocupacional e da população em geral a campos elétricos, magnéticos e eletromagnéticos, gerados por sistemas de energia elétrica. (SUPREMO TRIBUNAL FEDERAL, 2016, p. 01)

Percebe-se, pois, que o segmento de distribuição de energia é diferente de qualquer outro, requerendo cuidados especiais. Não obstante, os perigos não atingem apenas aos trabalhadores deste segmento, mas qualquer pessoa que tenha contato com eletricidade, ou seja, todos os usuários também estão sujeitos a acidentes (OLIVEIRA; VEIGA, 2013, p. 94). Noutros termos, o dano sucedido no ambiente de trabalho produtor e distribuidor de energia não repercute apenas no espaço produtivo da empresa, mas pode ir além gerando também consequências danosas para os próprios consumidores.

Torna-se evidente o caráter difuso do direito ao meio ambiente equilibrado, notadamente do ambiente laboral que comanda a produção e distribuição de energia. Ainda que empregados que trabalhem nestes locais, consumidores de energia das presentes gerações, bem como consumidores de energia das futuras gerações se destaquem como destinatários do referido direito difuso, é evidente que toda a coletividade - atual e futura - anseia e depende de um meio ambiente laboral produtor e distribuidor de energia marcadamente equilibrado, já que este não influi somente nestas atividades relativas ao mencionado bem, mas na qualidade do meio ambiente em geral, o qual the representa qualidade de vida.

As práticas difundidas na empresa, além de proporcionar um ambiente de trabalho melhor, tem o objetivo de serem absorvidas pelas pessoas, para serem praticadas, também, fora do local de trabalho, quer sejam por empregados próprios ou terceirizados, proporcionando o bemestar da família, multiplicando-se para toda a sociedade (OLIVEIRA; VEIGA, 2013, p. 94).

Partindo desse pressuposto e constatando que o meio ambiente laboral exerce significativa importância para o homem individualmente considerado, bem como para a coletividade em geral, seu pleno desenvolvimento exige a dignidade das condições sob as quais trabalha. Grande razão assiste, portanto, a um forte empenho para a efetivação do equilíbrio no ambiente de trabalho que produz e distribui energia, tendo em vista a evidente repercussão das condições a ele relativas sobre a população em geral, mormente, quando se analisa que o ambiente de trabalho daqueles que laboram nesse tipo de atividade pode se dá no próprio meio social em que se encontra o beneficiário do serviço.

Como se não bastasse a influência que exercem sobre a saúde do empregado, bem como sobre sua convivência familiar e negócios de seu empregador, os elementos que fazem parte do meio ambiente laboral que produz e distribui energia elétrica repercutem diretamente sobre uma infinidade de outras situações e pessoas. Dentre essas, é possível destacar a multidão de pessoas que usufruem da energia, e certamente serão afetadas pela interrupção ou queda de seu fornecimento, ou mesmo pelas notícias de que sua produção e distribuição estão ocorrendo de maneira prejudicial ao meio ambiente ou aos operários. 
A essencialidade de tais atividades de produção e distribuição de energia corrobora a ideia de que o ambiente de trabalho onde são exercidas deve gozar de equilíbrio, bem como que a coletividade em geral é merecedora do direito ao referido meio ambiente laboral equilibrado. Tal fato se evidencia na própria legislação infraconstitucional pátria, que, por meio do art. 10 da Lei 7.783/89 (Lei de Greve), reconheceu o caráter essencial da produção e distribuição de energia elétrica, que por interpretação extensiva, resulta no entendimento de que a produção e distribuição de qualquer fonte energética devem ser consideradas serviços essenciais.

Em vista disso, não restam quaisquer dúvidas acerca da relação entre o meio ambiente de trabalho que produz e distribui energia marcadamente equilibrado e o desenvolvimento sustentável, tanto sob a perspectiva ecológica, quanto humana, que abrange não apenas os trabalhadores, mas também a sociedade consumidora. Tendo em vista que aquele é corolário do direito à vida, já que a dignidade laboral é uma das facetas deste, a efetivação do direito ao equilíbrio do meio ambiente de trabalho responsável pela produção e distribuição da energia contribui para a qualidade de vida de uma vasta coletividade de pessoas, compatibilizando com o pleno desenvolvimento humano e social.

\section{NECESSIDADE DE CONJUGAÇÃO DE ESFORÇOS PARA A PROTEÇÃO DO MEIO AMBIENTE LABORAL RESPONSÁVEL PELA PRODUÇÃO E DISTRIBUIÇÃO DE ENERGIA: IMPLICAÇÃO DE SUA NATUREZA DIFUSA}

O legislador brasileiro, infraconstitucional e constitucional, procurou estabelecer normas que assegurassem proteção jurídica a este bem também no ordenamento jurídico pátrio. Sendo assim, merece destaque a Lei no 6.938/1981, que, ao tratar da Política Nacional do Meio Ambiente, visava conferir proteção integral ao meio ambiente, definindo-o em seu art. $3^{\circ}$ como "o conjunto de condições, leis, influências e interações de ordem física, química e biológica, que permite, abriga e rege a vida em todas as suas formas". Quanto ao âmbito constitucional, constata-se que a Constituição Federal de 1988 demonstrou atenção relevante para com o direito ao meio ambiente sadio e equilibrado, determinando em seu art. 225 que se trata de direito de todos, bem de uso comum do povo e essencial à sadia qualidade de vida, merecendo ser tutelado pelo Poder Público e pela coletividade.

Tendo em conta o caráter difuso do meio ambiente, a prescrição constitucional de que os setores público e privado devem se empenhar para protegê-lo é plenamente compreensível. Destarte, tendo em vista que o meio ambiente laboral faz parte daquele - sendo lá que o homem passa grande parte da sua vida -, com razão merece a conjugação dos esforços de todos para sua preservação.

Seguindo esta lógica, Milhoranza e Jaeger (2015, p. 1) destacam que a Carta Magna de 1988 é a responsável pela inclusão da preocupação com o meio ambiente do trabalho no sistema jurídico, compatibilizando com a ideia de desenvolvimento, aduzindo que a Constituição Federal de 1988 foi a primeira a se preocupar com o tema aqui tratado, incluindo, no sistema jurídico, o meio ambiente de trabalho como um dos aspectos mais importantes do meio ambiente, e recebendo a proteção constitucional adequada. A Magna Carta adotou dois objetos para tutelar a questão ambiental: um imediato que é a qualidade do meio ambiente em todos os seus aspectos, e outro mediato que é a saúde, a segurança e o bem-estar do cidadão. 
Considerando a relação entre o processo de desenvolvimento e o meio ambiente laboral, destaca-se a necessidade de todos preservarem o ambiente responsável pela produção e distribuição de energia. Tendo em vista que as condições, elementos e situações que lhe dizem respeito apresentam ampla repercussão e podem trazer benefícios para uma vasta quantidade de pessoas (que já vivem e que ainda viverão), bem como para plantas e animais, é indiscutível que todos têm o dever de zelar pela sua integridade.

Empregadores, com grande razão, devem garantir condições de labor compatíveis com a ideia de desenvolvimento humano; contudo, não se deve esquecer que a coletividade em geral e o Poder Público também devem dar suas contribuições. Tendo em vista que o clima no ambiente de trabalho, a potencialidade dos equipamentos utilizados, a degradação dos recursos naturais energéticos, bem como o conforto oferecido aos empregados que lidam com a produção e distribuição de energia são decisivos para o equilíbrio do seu ambiente de labor, a coletividade deve fazer sua parte e, dentre outras coisas, dar sua parcela de contribuição à paralisia, ou mesmo reversão, do aquecimento global, contenção da inflação (possibilitando que os patrões possam optar por máquinas e equipamentos que facilitam o trabalho dos operários, bem como para que possam oferecê-los espaços ou equipamentos que lhes garantam maior conforto) e desperdício de recursos naturais (evitando o labor excessivo).

Além disso, o Poder Público deve se empenhar para garantir normas protetivas do ambiente de trabalho que produz e distribui energia, considerando os desafios que os trabalhadores enfrentam para planejar e operar os equipamentos, bem como a pressão que sofrem para garantir o abastecimento de energia à demanda respectiva; sendo assim, o estabelecimento de sanções aos empregadores que descumprem as prescrições protetivas se torna valioso mecanismo de tutela do referido meio laboral, nas mãos do Poder Público, que pode efetivá-lo ou determinar sua observância pelos instrumentos privados.

Diante disso, sobressai a importância da educação e da conscientização ambientais, enquanto meios aptos a incutir em quaisquer agentes que influenciam na qualidade do meio ambiente laboral - notadamente do que produz e distribui energia - a necessidade de preservá-lo.

A educação ambiental merece ser vista como um importante instrumento para a garantia do direito ao meio ambiente do trabalho equilibrado, inclusive, do meio ambiente laboral responsável pela produção e distribuição da energia. Considerando sua capacidade para despertar e formar uma consciência ecológica para o exercício da cidadania, revela-se como uma estratégia plausível para preservar e recuperar as áreas atingidas pela má utilização dos recursos naturais (MASSINE, 2010).

A conscientização ambiental conduz ao entendimento de que, para que se garanta a qualidade de vida, o meio ambiente deve ser tutelado, e com grande razão o meio ambiente laboral, já que é nele onde o ser humano despende grande parte do seu tempo e dedicação. O ambiente do trabalho merece, pois, ser um dos principais alvos dos esforços coletivos para a preservação ambiental.

Destacando que a educação ambiental é necessária para a efetivação de um meio ambiente sustentável, Massine (2010, p. 2757) aponta que deve ser vista como um instrumento essencial para a viabilidade do desenvolvimento pleno, sadio e harmônico, despertando a percepção ambientalista por meio de mudanças nos valores, nas ações, nos pensamentos, nas metodologias e nos hábitos humanos.

Com relação à educação ambiental como fator para a concretização de um meio ambiente de trabalho produtor e distribuidor de energia ecologicamente equilibrado, é importante destacar o papel da CIPA (Comissão Interna de Prevenção de Acidentes), a quem compete a atribuição 
de avaliar os riscos laborais internos da empresa e informar os trabalhadores, como também atuar junto ao empregador requerendo uma política preventiva eficaz, que contemple não apenas os colaboradores da unidade produtiva, mas também a sociedade como um todo.

Além disso, saliente-se que os esforços coletivos para a preservação do ambiente laboral que produz e distribui o referido bem essencial coadunam com os princípios da precaução e da prevenção. Ambos buscam evitar que o dano ocorra, imprimindo uma nova interpretação ao art. $5^{\circ}$, XXXV, da Constituição Federal de 1988 (o qual dita que nenhuma ameaça ou lesão a direito será desamparada pelo Poder Judiciário), no sentido de valorizar a não efetivação do dano mais do que sua reparação. Considere-se, todavia, que se diferenciam na medida em que enquanto o princípio da prevenção procura evitar ou corrigir danos previsíveis, o princípio da precaução visa evitar o dano ainda imprevisto, por meio de adoção de medidas acautelatórias gerais, considerando o risco abstrato e geral (GEMIGNANI; GEMIGNANI, 2012).

Pode-se constatar a complementaridade entre os referidos princípios, sobretudo, quando se procura prevenir a ocorrência de danos no ambiente de trabalho, em razão de que se passa a analisar se os riscos nele presentes são conhecidos ou não. Nesse sentido, Gonçalves (2014, p. 10) aponta que, primeiramente, deve-se averiguar a existências de riscos à saúde no meio ambiente do trabalho para então implantar as medidas de prevenção e proteção, por meio das quais se busca eliminar ou minimizar o risco presente no ambiente. Defende a referida doutrinadora que, quando o risco laboral não é conhecido ou passível de determinação, a solução deve ser colhida no direito ambiental, que soluciona o problema de riscos desconhecidos ou irreversíveis através do princípio da precaução.

Tendo em vista que o meio ambiente laboral relativo à produção e distribuição de energia está permeado de riscos à saúde dos trabalhadores que nele operam, os quais, sem dúvida, repercutem sobre uma infinidade de pessoas direta ou indiretamente dependente do bem que deste ambiente provém, é plenamente necessária a aplicação dos mencionados princípios da precaução e da prevenção no ambiente de labor destacado. A minuciosidade do trabalho lá realizado, contando com equipamentos sofisticados e de operação delicada e dificultosa, bem como com o constante contato com materiais de tecnologia avançada ou aplicação não muito conhecida, demonstram que os serviços de produção e distribuição de energia merecem detida atenção quantos aos riscos que oferecem aos operários e pessoas nele envolvidas.

Gonçalves aponta que a adoção de medidas acautelatórias gerais para obstaculizar riscos imprevisíveis oferecidos pelo meio ambiente - precaução - está relacionada à qualidade de vida futura, fazendo nascer uma relação entre os princípios da precaução e da equidade intergeracional, nos seguintes termos:

\footnotetext{
Ao se tratar do princípio da precaução a questão intergeracional é intrinsecamente relacionada, pois o objetivo desse princípio é pensar na qualidade de vida futura, tendo como objeto a eliminação de possíveis danos que poderiam ser causados para as gerações futuras, e, além disso, entregar às gerações futuras um meio ambiente da forma em que o recebemos, garantindo as condições mínimas já conquistadas, podendo eles decidirem o que fazer dali em diante, conservando assim as opções, a qualidade e o acesso que formam assim, o chamado princípio da equidade intergeracional. (GONÇALVES, 2014, p. 18).
}

Gemignani e Gemignani (2012, p. 274-275) salientam esse caráter cíclico da defesa ao meio ambiente de trabalho ao destacarem que fomentar a melhoria das condições de trabalho, para que o ambiente seja saudável e seguro, cria um círculo virtuoso em benefício de todos os envolvidos, na medida em que gera vantagens para o empregador, que não perde o tempo e o 
dinheiro investidos no treinamento e pode contar com um empregado sadio e bem treinado; diminui o número de acidentes e doenças profissionais, minimizando gastos previdenciários com auxílio-doença e aposentadorias precoces, assim como evita o comprometimento da empregabilidade futura do trabalhador, a desagregação familiar e os casos recorrentes de alcoolismo e violência doméstica.

Em vista disso, resta evidente que todos devem se empenhar para garantir o equilíbrio do meio ambiente laboral produtor e distribuidor de energia, tomando a consciência de que este processo é realmente necessário, já que as condições de trabalho, elementos e situações que têm lugar nesse espaço laboral repercutem socialmente para uma grande parcela da população e podem trazer benefícios para uma vasta quantidade de pessoas (que já vivem e que ainda viverão). Sem dúvida, a educação ambiental é um instrumento à serviço da concretização do referido direito, tendo em vista que contribui para a assimilação individual e coletiva de sua importância, seja para as gerações presentes ou para as futuras, assim como para os que laboram diretamente no setor ou para quem sequer tem contato direto com ele. Os princípios da precaução e da prevenção - que ocupam o posto de princípios internacionais do Direito Ambiental - são mecanismos que, assimilados pela coletividade em geral e pelo setor público, devem ser vistos como instrumentos à serviço do equilíbrio no meio ambiente laboral responsável pela produção e distribuição de energia.

\section{CONCluSÃo}

A nova concepção de desenvolvimento exige que a organização do meio ambiente de trabalho esteja dissociada da ideia de crescimento econômico a todo custo e requer que se assegure, antes de qualquer outra pretensão, sua parcela de contribuição para a qualidade de vida dos trabalhadores e demais envolvidos, direta ou indiretamente, na atividade produtiva. Tal concepção se coaduna com a natureza jurídica que foi atribuída ao trabalho no texto da Constituição vigente (art. $1^{\circ}, \mathrm{IV}$; art. 170, caput; art. 193), que o encara como valor social.

Sendo o direito ao meio ambiente do trabalho equilibrado, assegurado tanto no plano internacional como no nacional - e neste, nos seus âmbitos constitucional e infraconstitucional percebe-se que o primeiro passo para sua observância já foi dado, qual seja, sua positivação. Com relação ao ambiente laboral, é imprescindível que ele seja capaz de assegurar o pleno desenvolvimento humano e social, tanto dos trabalhadores, quanto da coletividade em geral.

Da mesma forma deve ocorrer com relação ao meio ambiente de trabalho responsável pela produção e distribuição de energia. O bem que dele provém é indiscutivelmente essencial para a qualidade de vida do homem, que dele passou a depender, utilizando-o em diversas atividades que fazem parte do seu cotidiano.

Contudo, não somente a essencialidade da energia demonstra a relação entre o processo de desenvolvimento e o meio ambiente laboral que a produz e distribui. Há que se considerar que no referido ambiente os sujeitos implicados no processo de produção e distribuição merecem toda a proteção jurídica atinente aos direitos sociais, humanos, ou mesmo relativa às disposições trabalhistas que garantem segurança e dignidade no âmbito laboral. Além disso, convém destacar a repercussão social, ambiental e cultural proveniente das condições sob as quais ocorre a produção e a distribuição de energia, mormente, quando se analisa que as atividades dos trabalhadores desse setor, ou seja, o seu ambiente laboral, pode ser, inclusive, a casa do consumidor de energia ou o espaço geográfico onde ele vive, o que implica dizer que o próprio usuário pode figurar como um interveniente direto desse ambiente de trabalho específico. 
Como decorrência do nítido caráter difuso do meio ambiente onde são realizadas tais atividades, muitas pessoas podem sentir os reflexos da diminuição ou suspensão da produção ou distribuição energética em virtude de más condições laborais, ou mesmo do esgotamento das matérias primas lá utilizadas, em virtude de desperdícios no processo produtivo. Também pode haver um forte impacto no consumo de energia, caso as condições de trabalho dos colaboradores do setor não sejam adequadas e tal fato se torne conhecido socialmente. Também é imperioso levar em conta a repercussão social que poderá acontecer caso chegue ao conhecimento público que o processo realizado nesse ambiente degrada os recursos ambientais, ao ponto de provocar sua escassez em um futuro próximo.

As práticas utilizadas dentro da unidade produtiva que produz e distribui energia devem ser pensadas e planejadas para garantir, em primeiro lugar, o desenvolvimento integral do trabalhador desse setor, mas devem, também, contemplar a sociedade como um todo que deve ser conscientizada dos riscos que giram em torno da utilização desse bem essencial, como também da necessidade de preservação das fontes energéticas. Tudo isso para estabelecer uma responsabilização social, que começa dentro da empresa, através da CIPA, e deve continuar fora dela, junto à sociedade civil, a quem compete preservar as fontes energéticas, fiscalizar o cumprimento das normas de proteção que devem ser implementadas no ambiente de trabalho e daquelas normas que devem ser levadas a cabo pelo empresário fora da empresa para proteger o destinatário do produto de eventuais acidentais, que podem repercutir tanto do ponto de vista do ambiente natural, como também no âmbito laboral.

A conjugação de esforços para adequar as práticas do meio ambiente de trabalho produtor e distribuidor de energia a um projeto que garanta o desenvolvimento humano e social, em especial, do trabalhador, mas que alcance, de forma geral, toda a coletividade, deve ser a tônica perseguida pelo setor, que deve ser fiscalizado tanto pelos particulares, quanto pelo Poder Público.

O caminho para a concretização desse objetivo é a educação ambiental, atribuindo à sociedade e aos indivíduos separadamente considerados uma parcela da responsabilidade de proteger o ambiente produtor e distribuidor de energia, o que se coaduna com a necessidade de prevenção dos riscos ambientais, que, nos termos do art. 225, caput, da atual Constituição, figura como uma obrigação do Poder Público e da coletividade conjuntamente, já que o meio ambiente se caracteriza como bem de uso comum do povo.

\section{REFERÊNCIAS}

BERCOVICI, Gilberto. Constituição econômica e desenvolvimento: uma leitura a partir da Constituição de 1988. São Paulo: Malheiros, 2005.

COSTA, Cristiane Ramos. O direito ambiental do trabalho e a insalubridade: aspectos da proteção jurídica à saúde do trabalhador sob o enfoque dos direitos fundamentais. São Paulo: LTr, 2013.

COUTINHO, Ana Luísa Celino; BARACHO, Hertha Hurquiza. A efetividade do princípio da capacidade contributiva como requisito para o desenvolvimento fiscal sustentável. In: BASSO, Ana Paula (Org.). Direito e Desenvolvimento Sustentável. Curitiba: Juruá, 2013. p. 149-164.

DAVIS, Kevin E.; TREBILCOCK, Michael J. A relação entre lei e desenvolvimento: otimistas versus céticos. (Tradução de Pedro Maia Soares). Revista Direito GV, São Paulo, v. 5(1), jan./ jun.2009, p. 217-268. 
FINATI, Cláudio Roberto. O valor social do trabalho. Revista do Tribunal Regional do Trabalho da 15 Região, São Paulo, n. 8, 1996, p. 28-39.

FIORILlO, Celso Antonio Pacheco. Curso de direito ambiental brasileiro. São Paulo: Saraiva, 2000.

FURTADO, Celso. Os desafios da nova geração. Revista de Economia Política, v. 24, nº 4 (96), out./dez.2004, p. 483-486.

GEMIGNANI, Tereza Aparecida Asta; GEMIGNANI, Daniel. Meio ambiente de trabalho: precaução e prevenção. Princípios norteadores de um novo padrão normativo. Revista TST, Brasília, v. 78, nº 1, jan./mar. 2012, p. 258-280.

GOLDEMBERG, José. Energia e desenvolvimento. Estudos Avançados, São Paulo, Instituto de Estudos Avançados da Universidade de São Paulo, v. 12, no 33, 1998. Disponível em: <http:// bit.ly/1xrS20p> Acesso em 08/01/2016.

GONÇALVES, Juliana Seawright. Direito fundamental a um meio ambiente do trabalho equilibrado e saudável: o princípio da precaução e a questão intergeracional. In: MISAILIDIS, Mirta Gladys Lerena Manzo de; SILVA, Lucas Gonçalves da; BARBATO, Maria Rosaria. (Coords.) Anais do XXIII Encontro Nacional do CONPEDI/UFSC (2010). Direito do trabalho. Florianópolis: CONPEDI, 2010. p. 72-91.

GONÇALVES, Heloísa Alva Cortez; LOPES, Mariane Helena. A dignidade da pessoa humana e o valor social do trabalho. Direito Econômico e Socioambiental, Curitiba, v. 4, $\mathrm{n}^{\mathrm{o}} 2$, jul./dez. 2013, p.129-145.

GRAU, Eros Roberto. A ordem econômica na Constituição de 1988. São Paulo: Malheiros, 2007.

MASSINE, Maiara Cristina Lima. Sustentabilidade e educação ambiental - considerações acerca da Política Nacional de educação ambiental. In: Anais do XIX Encontro Nacional do CONPEDI/UFC (2010). Direito e educação. Florianópolis: Fundação Boiteux, 2010. p. 2757-2770.

MILHORANZA, Mariângela Guerreiro; JAEGER, Paula. O meio ambiente e o meio ambiente do trabalho: um estudo à luz do direito coletivo laboral no direito brasileiro e no direito comunitário europeu. Processos coletivos, v. 6, nº 4, 2015. Disponível em: http://www.processoscoletivos.net> Acesso em 08/01/2016.

NASCIMENTO, Amauri Mascaro. A defesa processual no meio ambiente do trabalho. Revista LTr, v. 63, no 5, maio/1999, p. 583-587. O direito à saúde e segurança no meio ambiente do trabalho.

OLIVEIRA, Sebastião Geraldo de. Proteção jurídica à saúde do trabalhador. 2. ed., São Paulo: LTr, 1998.

OLIVEIRA, Flávia de Paiva Medeiros; OLIVEIRA, Daniela Paiva. Meio ambiente do trabalho e novas perspectivas: uma proposta para o desenvolvimento integral do trabalhador. In: COUTINHO, Ana Luisa Celino; BASSO, Ana Paula; CECATO, Maria Áurea Baroni; FEITOSA, Maria Luiza Pereira de Alencar Mayer (coords.). Direito, Cidadania e Desenvolvimento. Florianópolis: Conceito Editorial, 2012, p. 149-161.

OLIVEIRA, Maristela; VEIGA, Cristiano Henrique Antonelli da. Segurança e saúde no trabalho em cooperativa de distribuição de energia elétrica: percepção dos colaboradores. Revista Ação Ergonômica, v. 8, n. 2, 2013, p. 92-101. Disponível em: <http://www.abergo.org.br/revista/index.php/ae/issue/view/20>. 
PADILHA, Norma Sueli. Do meio ambiente do trabalho equilibrado. São Paulo: LTr, 2002. ROCHA, Julio Cesar de Sá da. Direito ambiental e meio ambiente do trabalho: dano, prevenção e proteção jurídica. São Paulo: LTr, 1997.

RODRIGUES, Cláudia. A (Des)valorização do trabalho humano pela Justiça do Trabalho. Jornal Trabalhista, São Paulo, v. 20, n. 961, 2003, p. 12-13.

SACHS, Ignacy. Caminhos para o desenvolvimento sustentável. Rio de Janeiro: Garamond, 2009.

SALOMÃO FILHO, Calixto. Regulação e desenvolvimento. In: SALOMÃO FILHO, Calixto (Orgs.). Regulação e Desenvolvimento. São Paulo: Malheiros, 2002. p. 29-62.

SILVA, José Afonso da. Direito ambiental constitucional. 2. ed., São Paulo: Malheiros Editores, 1995.

SILVA, Müller Fernandes da. Segurança do Trabalho - Eletricidade. 2012. Disponível em: <http://www.ebah.com.br/content/ABAAAAg5IAA/seguranca-trabalho-eletricidade?part=2>. Acesso em: 30 jul. 2017.

SEN, Amartya. Desenvolvimento como liberdade. Tradução de Laura Teixeira Motta. São Paulo: Companhia de Bolso, 2007.

SUPREMO TRIBUNAL FEDERAL. Campos eletromagnéticos de linhas de energia devem respeitar padrões da OMS. 2016. Disponível em: <http://stf.jus.br/portal/cms/verNoticiaDetalhe.asp?idConteudo=318457>. Acesso em: 30 jul. 2017.

ROZA FILHO, Oswaldo Aristides. Segurança do trabalho em atividades com energia elétrica: um estudo baseado na interpretação da responsabilidade jurídica na NR-10. Campina Grande: UEPB, 2012.

TAVARES, André Ramos. Direito Constitucional Econômico. São Paulo: Método, 2011.

VEIGA, José Eli da. Desenvolvimento sustentável o desafio do século XXI. Rio de Janeiro: Garamond, 2010.

VITOR, Rodrigo Ribeiro. A energia eólica e sua relação com o desenvolvimento sustentável no Brasil. In: FEITOSA, Maria Luíza Pereira de Alencar Mayer; XAVIER, Yanko Marcius de Alencar; CLARK, Giovani. (Coords.). Anais do XXIII Congresso Nacional do CONPEDI/UFPB. Direito econômico, energia e desenvolvimento. Florianópolis: CONPEDI, 2014. p. 125-147.

Recebido em: 03 abr. 2017.

Aceito em: 26 out. 2017. 